\title{
Long-term vertigo control after cochlear implantation in patients with end-stage Menière's disease
}

\section{A retrospective questionnaire-based cross-sectional study}

\author{
Annabella Kurz $(\mathbb{D})$ Alice Auinger - Christoph Arnoldner
}

Received: 4 July 2019 / Accepted: 30 December 2019 / Published online: 29 January 2020

(C) The Author(s) 2020

\begin{abstract}
Summary
Background Menière's disease (MD) is a symptom complex which is characterized by episodes of vertigo, tinnitus and fluctuating sensorineural hearing loss, which worsens during the course of the disease. Objective Vertigo attacks (MD functional level scale) before compared to after cochlear implantation in patients with end-stage MD.

Design and patients In this questionnaire-based crosssectional study eight patients with end-stage MD, who received a cochlear implant (CI) were analyzed.

Main outcome measure The effect of the CI on vertigo was measured preoperatively and postoperatively with the Menière's disease functional level scale and the Menière's disease outcome questionnaire. The primary outcome parameter influence of vertigo attacks on daily living was analyzed using the non-parametric Wilcoxon signed rank test before and after CI.

Setting Department of otolaryngology of a medical university.

Results The primary outcome measure influence of vertigo attacks on daily living as measured by the MD functional level scale improved significantly after CI. Conclusion A CI can be an adequate treatment for vertigo attacks in patients with end-stage MD; however, due to the small sample size additional (multicenter) trials are necessary to confirm the findings.
\end{abstract}

Keywords Surgery · Endolymphatic hydrops · Deafness · Dizziness · Tinnitus

Dr. A. Kurz, MD $(\bowtie) \cdot A$. Auinger, MD · C. Arnoldner, MD Department of Otolaryngology, Head and Neck Surgery, Medical University of Vienna - AKH Vienna, Waehringer Guertel 18-20, 1090 Vienna, Austria annabella.kurz@meduniwien.ac.at

\section{Introduction}

Menière's disease (MD) is a symptom complex which is characterized by episodes of vertigo, tinnitus, aural fullness and fluctuating sensorineural hearing loss, which worsen during the course of the disease [1].

This can lead to deafness on the affected side in many patients. Reported rates range from $5 \%$ to $50 \%$. The incidence of bilateral deafness secondary to MD is rare and ranges from $1 \%$ to $6 \%$ [2].

Recommended MD treatment includes lifestyle modifications followed by administration of diuretics and betahistine, intratympanic corticosteroids, endolymphatic sac surgery, medical destructive treatment (intratympanic gentamicin treatment), and surgical destructive treatment (labyrinthectomy \pm cochlear implantation, vestibular neurectomy) [3].

The impact of cochlear implantation (CI) on vertigo in MD is not yet fully understood. Whereas some studies reported a clear improvement after CI [4-6] others found little or no effect [6-8].

In $\mathrm{MD}$, labyrinthectomy was first performed in 1895 as a destructive but very effective option for patients with treatment-resistant vertigo [9]. Recently this treatment has become more interesting again as hearing can be restored with a cochlear implant in a simultaneous procedure [10-13].

In 2013 Hansen et al. reported 10 end-stage unilateral MD patients who underwent labyrinthectomy and simultaneously CI, vertigo control was achieved in all of the cases [14]. This is not surprising as both modalities per se have been proven to be beneficial; however, the question whether cochlear implantation alone would improve vertigo spells in MD patients was not answered. In a retrospective study, Mukherjee et al. compared $22 \mathrm{MD}$ patients (19 bilateral and 3 unilateral $\mathrm{MD}$ ) who underwent $\mathrm{CI}$ only to $6 \mathrm{MD}$ (5 unilateral and 1 bilateral) patients who received CI 
Table 1 Patient characteristics

\begin{tabular}{|c|c|c|c|c|c|c|c|c|}
\hline Pat & $\begin{array}{l}\text { Age at implantation } \\
\text { (years) }\end{array}$ & Sex & $\begin{array}{l}\text { Bilateral MD } \\
(y / n)\end{array}$ & Cochlear implant & $\begin{array}{l}\text { Duration of deafness } \\
\text { (years) }\end{array}$ & $\begin{array}{l}\text { Time from } \mathrm{Cl} \text { to fol- } \\
\text { low-up (years) }\end{array}$ & $\begin{array}{l}\text { Follow-up } \\
\text { date }\end{array}$ & $\begin{array}{l}\text { Treatment prior } \\
\text { to } \mathrm{Cl}\end{array}$ \\
\hline 1 & 78.3 & M & $n$ & $\begin{array}{l}\text { MED-EL SONATA } \\
\text { STANDARD }\end{array}$ & 20.2 & 6.8 & 04.2018 & Conservative \\
\hline 2 & 63.2 & M & $y$ & $\begin{array}{l}\text { MED-EL COMBI } \\
40+\text { STANDARD }\end{array}$ & 28.5 & 13.6 & 05.2016 & Conservative \\
\hline 3 & 48.7 & M & $n$ & $\begin{array}{l}\text { MED-EL SYN- } \\
\text { CHRONY FLEX } \\
28\end{array}$ & 20.8 & 4.2 & 07.2016 & Conservative \\
\hline 4 & 67.9 & $\mathrm{~F}$ & $y$ & $\begin{array}{l}\text { MED-EL CON- } \\
\text { CERTO FLEX SOFT }\end{array}$ & 24.8 & 5.3 & 04.2018 & Conservative \\
\hline 5 & 70.5 & $\mathrm{~F}$ & $y$ & $\begin{array}{l}\text { MED-EL CON- } \\
\text { CERTO FLEX } 28\end{array}$ & $\mathrm{~N} / \mathrm{A}$ & 3.0 & 05.2016 & Tenotomy \\
\hline 6 & 67.6 & $\mathrm{~F}$ & $y$ & $\begin{array}{l}\text { MED-EL CON- } \\
\text { CERTO FLEX } 28\end{array}$ & 5.3 & 4.7 & 04.2018 & Conservative \\
\hline 7 & 70.3 & M & $n$ & $\begin{array}{l}\text { MED-EL PULSAR } \\
\text { FLEX } 28\end{array}$ & $\mathrm{~N} / \mathrm{A}$ & 5.6 & 05.2016 & Conservative \\
\hline 8 & 50.8 & M & $n$ & $\begin{array}{l}\text { MED-EL CON- } \\
\text { CERTO STANDARD }\end{array}$ & 18.5 & 2.5 & 06.2016 & $\begin{array}{l}\text { Gentamicin } \\
\text { injection }\end{array}$ \\
\hline Mean & 64.7 & - & - & - & 19.7 & 5.7 & - & - \\
\hline
\end{tabular}

in combination with simultaneous labyrinthectomy and to $3 \mathrm{MD}$ (2 unilateral and 1 bilateral) patients who received CI and delayed labyrinthectomy. Preoperatively in the CI only group two patients suffered from vestibular symptoms. Postoperatively long-lasting vestibular dysfunction occurred in three patients in the CI only group, whereas two of these patients presented with vestibular symptoms on the contralateral ear over many months. In the simultaneous CI group preoperatively six patients suffered from vertigo and stayed free of vertigo postoperatively [10]. Lustig et al. observed 9 CI MD patients, only 2 patients presented with vertigo attacks preoperatively, postoperatively only 1 patient suffered from vertigo in the first 3 months after implantation and stayed vertigo-free up to 4.5 years [4].

In summary, little is known about the impact of CI on vertigo in patients suffering from recalcitrant MD. For that reason, the primary aim was to evaluate if $\mathrm{CI}$ improves vertigo and secondary if $\mathrm{CI}$ improves the quality of life in patients with end-stage MD.

\section{Patients, materials and methods}

\section{Primary outcome}

This questionnaire-based cross-sectional study was performed at the department of otolaryngology, head and neck surgery of a university hospital and was approved by the local ethics committee. A total of eight patients suffering from MD according to the AAO guidelines and who received a cochlear implant (MED-EL [Elektromedizinische Geräte Gesellschaft m.b.H., Innsbruck, Austria]) due to severe sensorineural hearing loss were included in the study. The surgery was performed between June 2002 and
July 2013. All subjects were selected based on information from their patient charts (Table 1). All subjects were deaf on the MD ear preoperatively. Patients with bilateral MD received only unilateral CI, which was implanted on the side with the more pronounced hearing loss. Subjects were requested to answer several questionnaires from a preoperative and a present perspective at follow-up time. The questionnaires included the morbus Menière outcome questionnaire and the MD functional level scale [15]. The primary goal was to evaluate the effect of a CI on vertigo spells in patients with end-stage MD according to the functional level scale before compared to after CI. Secondary outcome measures were quantity of vertigo attacks ( $n$ per month) perioperatively (time period of 6 months before vs. 6 months after $\mathrm{CI}$ ) and quality of life measured by the morbus Menière outcome questionnaire.

\section{Statistical analysis}

Depending on distributional properties continuous data were expressed as medians (25th-75th percentile). Binary data were expressed as counts and relative frequencies. Changes in MD symptoms were assessed by the non-parametric Wilcoxon signed rank test. Multivariate regression analysis was used to assess influence of age, sex and time from diagnosis of MD to CI on the outcome parameter difference of number of vertigo attacks before vs. after CI. For data management and statistical analyses Microsoft Excel 2010 (Microsoft Corporation, Redmond, WA, USA) and IBM SPSS (version 21, IBM, Armonk, NY, USA) for Windows was used. A $p$-value of $<0.05$ was regarded to indicate statistical significance. Sample size calcu- 
Table 2 Primary and secondary outcome variables

\begin{tabular}{|l|l|l|l|}
\hline & Before $\mathrm{Cl}$ & \multicolumn{1}{|c|}{ After $\mathrm{Cl}$} & $p$-value \\
\hline Vertigo attacks (Menière's disease functional level scale) & $5(4-5)$ & $3(2-4)$ & 0.027 \\
\hline Quantity of vertigo attacks ( $n$ per month) perioperatively ${ }^{\mathrm{a}}$ & $2(1-4)$ & $1(0-1)$ & 0.058 \\
\hline Quality of life (Menière's disease outcome questionnaire) & $45(34-48)$ & $27(17-35)$ & 0.035 \\
\hline $\begin{array}{l}\text { Data are median (25th-75th percentile), unless otherwise stated } \\
\text { Cl cochlear implant } \\
\text { a } 6 \text { - month time period before Cl vs. 6-month time period after } \mathrm{Cl}\end{array}$ & & & \\
\hline
\end{tabular}

lation was not performed since this is a pilot study and no meaningful was available at that moment.

The study was approved by the local Ethics Committee. All procedures followed were in accordance with the ethical standards of the responsible committee on human experimentation (institutional and national) and with the Helsinki Declaration of 1975, as revised in 2008.

\section{Questionnaires}

The Menière's disease functional level scale reflects the influence of MD in patients daily living activities on a scale from 1 to 6 [15].

\section{Menière's disease outcome questionnaire}

This questionnaire consists of 40 questions which records the quality of life before and after a treatment for MD. A special emphasis is on the activities of daily living. A lower score yields a higher quality of life [16].

\section{Results}

This analysis included eight patients suffering from end-stage MD who received a CI (Table 1), four with unilateral MD and four with bilateral MD. Follow-up time after implantation ranged from 2.5-13.5 years (mean 6.7 years).

The primary outcome measure influence of vertigo attacks on daily living as measured by MD functional level scale improved significantly after CI (before vs. after CI: 5 (4-5) vs. 3 (2-4); $p=0.027$; Table 2). The secondary outcome quantity of vertigo attacks per month perioperatively decreased insignificantly after CI (before vs. after CI: $2(1-4)$ vs. $1(0-1) ; p=0.058)$, while the quality of life as measured by the Menière's disease outcome questionnaire improved significantly after CI (before vs. after CI: 45 (34-48) vs. 27 (17-35); $p=0.035$; Table 2).

In multivariate regression analysis no covariables were significantly predictive for the outcome parameter difference of number of vertigo attacks before vs. after CI.

\section{Discussion}

The impact of CI on vertigo in patients with MD is not yet fully understood; however, based on the assumed pathophysiology, patients may benefit from implan- tation as the inner ear is opened via the round window or cochleostomy and consequently pressure is relieved. Overall, some patients have only few vertigo attacks preoperatively reflecting the end-stage disease; others show no attacks due to previous surgery to control vertigo and some others still have no vertigo attacks even in the end-stage of MD [17].

In this study, in eight patients with end-stage MD it could be shown that CI improved vertigo and quality of life with follow-up times of 3-14 years.

The results are consistent with findings from McRackan et al. who examined 21 MD patients (unilateral or bilateral disease) after CI. Of these patients six suffered from vertiginous symptoms preoperatively. Postoperatively two patients were vertigo-free, three reported improvements and one had constant vertigo attacks [5]. Mick et al. investigated 20 patients with either unilateral or bilateral MD: 6 subjects suffered from at least 1 episode of vertigo in the year before surgery. Postoperatively, one patient continued to suffer from lightheadedness, which resolved spontaneously, five other patients reported chronic dizziness after implantation; however, these five patients had bilateral MD and were implanted only on one side [6].

It needs to be stated that in the abovementioned studies not all patients with MD were implanted on the affected side compared to the present study.

Fife et al. found no vertigo attacks postoperatively in 10 CI MD patients with a follow-up of 6 years amd 4 of these patients underwent surgical or chemical labyrinthectomy preoperatively [7].

Lustig et al. investigated seven patients with bilateral MD and two with unilateral MD after CI. Of these patients five had undergone previous surgery for vertigo control, e.g. sac decompression, shunting, perilymphatic fistula exploration and labyrinthectomy. Interestingly, only the labyrinthectomized patient suffered from vertigo in the first month of implantation [4]. Hence, vertigo control rates were clearly higher in the present study, where only one patient had a previous surgery for vertigo (tenotomy) (Table 1), another patient had received gentamicin injections.

The combination of labyrinthectomy and CI has been recently described as a successful tool of vertigo control and restoration of hearing [10-14]; however, after labyrinthectomy, postoperative vertigo can occur due to inadequate surgical removal of the vestibular sense organs, neuroma formation in the vestibule, and 
high regenerative potential of the vestibular nerve [18, 19].

In a study Doobe et al. reported 5 unilateral MD patients undergoing labyrinthectomy and CI with vertigo relief lasting more than 6 months [11]. Osborn et al. reported delayed CI 21 years after labyrinthectomy in a case report in a bilateral MD patient [20]. In contrast Hansen et al. performed simultaneous labyrinthectomy and CI in 10 unilateral MD patients to avoid a second anesthesia and ossification in the cochlea resulting in problems during implantation and reduction of deafness time. In all 10 unilateral MD patients vertigo control was achieved, 4 with a follow-up time less than 6 months and a few patients with a follow-up time 18-24 months [14]. Although labyrinthectomy is an adequate tool for vertigo relief, it is a destructive surgery and associated with a risk of cochlear ossification and impaired CI performance. In the present study, vertigo control was achieved with CI only. As a second step, labyrinthectomy could still be performed in patients with persistent vertigo attacks after CI implantation.

\section{Limitations of the study}

The small sample size and the retrospective character of this trial is a significant limitation.

\section{Conclusion}

In end-stage MD patients CI may control vertigo; however, due to the small sample size additional prospective (multicenter) trials are necessary to confirm these findings. Acknowledgements I thank PD Dr. Richard Brunner, $\mathrm{PhD}$ for
his support and proofreading.

Funding Open access funding provided by Medical University of Vienna.

Conflict of interest A. Kurz, A. Auinger, and C. Arnoldner declare that they have no competing interests.

Open Access This article is licensed under a Creative Commons Attribution 4.0 International License, which permits use, sharing, adaptation, distribution and reproduction in any medium or format, as long as you give appropriate credit to the original author(s) and the source, provide a link to the Creative Commons licence, and indicate if changes were made. The images or other third party material in this article are included in the article's Creative Commons licence, unless indicated otherwise in a credit line to the material. If material is not included in the article's Creative Commons licence and your intended use is not permitted by statutory regulation or exceeds the permitted use, you will need to obtain permission directly from the copyright holder. To view a copy of this licence, visit http://creativecommons.org/licenses/by/4.0/.

\section{References}

1. Schuknecht HF. Ablation therapy for the relief of Meniere's disease. Laryngoscope. 1956;66(7):859-70.

2. Shojaku H, Watanabe Y, Yagi T, Takahashi M, Takeda T, Ikezono T, et al. Changes in the characteristics of definite Meniere's disease over time in Japan: a long-term survey by the peripheral vestibular disorder research committee of Japan, formerly the Meniere's disease research committee of Japan. Acta Oto-laryngologica. 2009;129(2):155-60.

3. Nevoux J, Barbara M, Dornhoffer J, Gibson W, Kitahara T, Darrouzet V. International consensus (ICON) on treatment of Meniere's disease. Eur Ann Otorhinolaryngol Head Neck Dis. 2018;135(1S):S29-S32.

4. Lustig LR, Yeagle J, Niparko JK, Minor LB. Cochlear implantation in patients with bilateral Meniere's syndrome. Otol Neurotol. 2003;24(3):397-403.

5. McRackan TR, Gifford RH, Kahue CN, Dwyer R, Labadie RF, Wanna GB, etal. Cochlear implantationin Meniere's disease patients. Otol Neurotol. 2014;35(3):421-5.

6. Mick P, Amoodi H, Arnoldner C, Shipp D, Friesen L, Lin V, et al. Cochlear implantation in patients with advanced Meniere's disease. Otol Neurotol. 2014;35(7):1172-8.

7. Fife TA, Lewis MP, May JS, Oliver ER. Cochlear implantation in Meniere's disease. JAMA Otolaryngol Head Neck Surg. 2014;140(6):535-9.https://doi.org/10.1001/jamaoto.2014. 550.

8. Fina M, Skinner M, Goebel JA, Piccirillo JF, Neely JG, BlackO. Vestibular dysfunction after cochlear implantation. Otol Neurotol. 2003;24(2):234-42. discussion 42.

9. Belal A Jr.. Pathology as it relates to surgery of Meniere's disease. Adv Otorhinolaryngol. 1983;31:155-64.

10. Mukherjee P, Eykamp K, Brown D, Curthoys I, Flanagan S, Biggs N, et al. Cochlear implantation in Meniere's disease with and without labyrinthectomy. Otol Neurotol. 2017;38(2):192-8.

11. Doobe G, Ernst A, Ramalingam R, Mittmann P, Todt I. Simultaneous labyrinthectomy and cochlear implantation for patients with single-sided Meniere's disease and profound sensorineural hearing loss. Biomed Res Int. 2015;2015:457318.

12. Morgan M, Flood L, Hawthorne M, Raje S. Chemical labyrinthectomy and cochlear implantation for Meniere's disease - an effective treatment or a last resort? J Laryngol Otol. 1999;113(7):666-9.

13. KvetonJF,AbbottC,AprilM, DrumhellerG, CohenN,PoeDS. Cochlear implantation after transmastoid labyrinthectomy. Laryngoscope. 1989;99(6 Pt 1):610-3.

14. Hansen MR, Gantz BJ, Dunn C. Outcomes after cochlear implantation for patients with single-sided deafness, including those with recalcitrant Meniere's disease. Otol Neurotol. 2013;34(9):1681-7.

15. Monsell EM. New and revised reporting guidelines from the committee on hearingandequilibrium. American academy of otolaryngology-head and neck surgery foundation, Inc. Otolaryngol Head NeckSurg. 1995;113(3):176-8.

16. Kato BM, LaRouere MJ, Bojrab DI, Michaelides EM. Evaluating quality of life after endolymphatic sac surgery: the Meniere's disease outcomes questionnaire. Otol Neurotol. 2004;25(3):339-44.

17. Strupp M, Brandt T. Current treatment of vestibular, ocular motor disorders and nystagmus. Ther Adv Neurol Disord. 2009;2(4):223-39.

18. Belal A, Ylikoski J. Pathology as it relates to ear surgery II. Labyrinthectomy. JLaryngol Otol. 1983;97(1):1-10. 
19. Linthicum FH Jr., Alonso A, Denia A. Traumatic neuroma: a complication of transcanal labyrinthectomy. Arch Otolaryngol. 1979;105(11):654-5.

20. Osborn HA, Yeung R, Lin VY. Delayed cochlear implantation after surgical labyrinthectomy. J Laryngol Otol. 2012;126(1):63-5.

Publisher's Note Springer Nature remains neutral with regard to jurisdictional claims in published maps and institutional affiliations. 